\title{
A New Perspective for Saturation Flows at Signalized Intersections
}

\author{
Yetis Sazi Murat ${ }^{1 *}$, Murat Cetin² \\ 1 Department of Civil Engineering, \\ Faculty of Engineering, \\ Pamukkale University \\ 20070, Denizli, Turkey \\ 2 General Directorate of Highways, Headquarters of Second Region \\ 35100, Bornova, Izmir, Turkey \\ * Corresponding author, e-mail: sazimurat@gmail.com
}

Received: 03 August 2017, Accepted: 03 January 2019, Published online: 13 February 2019

\begin{abstract}
Saturation flow is one of the fundamental parameter that is used to define the level of service, to assign signal timings and other traffic operations. In the conventional approaches (Highway Capacity Manual, Canadian Capacity Guide etc.) base value is adjusted by the parameters that represent field and traffic conditions. Although the results obtained are acceptable, the adjustment parameters may not reflect the field conditions properly in many countries and does not represent any effects on driver behavior. This paper presents a new formula for saturation flow based on driver behavior and some vehicle characteristics. In this formula, mean length, headway and acceleration rates of vehicles, saturation speeds of intersection and mean reaction time of vehicles in a queue are considered. The formula is tested with field data and compared to the values obtained by the HCM, CCG (Canadian Capacity Guide) and the Akcelik approaches. Based on these comparisons, it is commented that estimation of the new formula is promising.
\end{abstract}

Keywords

saturation flow, signalized intersection, capacity, driver behavior, vehicle time headway, traffic signal control

\section{Introduction}

Saturation flow rate is defined as the flow rate per lane at which vehicles can pass through a signalized intersection in unit time [1]. It is one of the most important design parameter that is used in determining capacity of signalized intersections. It is also used for calculation of signal timing parameters in many countries.

The general descriptions of saturation flow presented in the Highway Capacity Manual (HCM), the Canadian Capacity Guide (CCG) for Signalized Intersections, and Australian Road Research Board special report on traffic signal capacity and timing analysis are more or less identical for similar close-to-ideal intersection conditions [2]. In conventional analytical approaches (HCM, CCG, Akcelik etc.) effects of physical conditions and parameters such as lane width, turning radius, bus blockage, left turn lane etc. are taken into consideration. However, many researches focus on development of saturation flow determination approaches regarding different parameters and traffic conditions $[3,4,5,6,7]$
Effects of saturation headways on capacity for protected left turn phase are investigated by Xuon et al. [8]. Chen et al. considered saturation flow analysis of shared left-turn lane at signalized intersections in Japan [9]. The HCM and JSTE (Japan Society of Traffic Engineering) guideline is analyzed and overestimated results are obtained. Sun et al. investigated effect of rainy weather on saturation flow rate and start-up lost time of dual left lanes at signalized intersections and found about $21-33 \%$ decrease in start-up lost times and 3-7 \% in saturation flows.

Shao et al. dealt with saturation flow rate and influencing factors in China [10]. Micro-simulation modelling approach for estimation of saturation flow at signalized intersections is considered by Hossain [11].

Susilo and Solihin considered approach width and modified a saturation flow formula regarding field observations [12]. Lane types and effect of heterogeneous traffic flows are investigated by Shang et al. [13]. 
It has been known that lane usage, lane capacity, vehicle time headway and driver behaviors are varied by countries [14]. Thus, many researchers focused on determination of saturation flows considering local conditions. Effect of lane width on saturation flow has also been considered by Shigenori et al. In this study, findings show that saturation flow value may be decreased if lane width is less than $3.00 \mathrm{~m}$ [15]. Joseph and Chang dealt with effects of user specifications on saturation flow [16]. Lin and Thomas considered determination of saturation flow by queue discharging [17]. Radhakrishnan and Mathew considered saturation flow model by HCM and stated that HCM model may be inaccurate for mixed traffic composition especially in case of higher rate of heavy vehicles. They recommended Passenger Car Unit (PCU) value based approach to remove deficiencies [18]. Hadiuzzaman also considered effect of traffic composition on saturation flow, recommended PCU values for saturation flow and developed some delay models [19]. Turning flows on red signal are considered by Stewart and Hodgson. A regression analysis resulted in the production of a simple equation for estimating right turn on red saturation flow rates. It is found that the headway acceptance behavior of drivers varied both spatially and temporally [20]. Rahman et al. used Analysis of Variance (ANOVA) approach for vehicle time headways in determination of saturation flows at signalized intersections [21]. L. L. Vien et al. developed a formula for determination of saturation flow considering passenger car equivalent value of traffic flows. The formula is tested with field studies [22].

As summarized above, many researchers have been focused on effective parameters of saturation flow and calibration of formulas. The existing approaches (i.e. HCM, CCG, ARRB etc) are insufficient because of the selected parameters, although it is intended to improve a model that can be generalized using them. The parameters used reflect only traffic conditions and geometric conditions. But it is known that driver behaviors and vehicle characteristics have considerable effects on saturation flow.

The main aim of this study is to define a new perspective for saturation flows at signalized intersections regarding different parameters. In this study, the parameters including driver behaviors (such as following headways, saturation flow speeds, reaction time, etc) are taken into consideration. A new formula including the selected characteristics is developed and tested. Moreover, the effects of the parameters on saturation flow are investigated regarding previous studies. Results of these investigations are also reported in related sections of this work.
This study is organized as follows; the saturation flow phenomenon is introduced in the next section. The new formula for saturation flow and the model structure are explained in the following section. After that, details of the method, case studies and influencing factors are given respectively. The results obtained from the research findings are summarized in the conclusion.

\section{Saturation flow}

Saturation flow is dependent to many variables such as intersection geometry, vehicle type, traffic conditions, driver behaviour etc. It can also be changed by time of day and location. Thus, the assignment of the correct rate is a major and difficult task for many researchers. In HCM, the following equation is suggested for saturation flows.

$S=S_{o} N f_{w} f_{H V} f_{g} f_{p} f_{b b} f_{a} f_{L U} f_{L T} f_{R T} f_{L p b} f_{R p b}$,

where $S=$ saturation flow rate for subject lane group, expressed as a total for all lanes in lane group (veh/h), $S_{0}$ = base saturation flow rate per lane (pc/h/ln); $N=$ number of lanes in lane group; $f_{w}=$ adjustment factor for lane width; $f_{H V}=$ adjustment factor for heavy vehicles in traffic stream; $f_{g}=$ adjustment factor for approach grade; $f_{p}=$ adjustment factor for existence of a parking lane and parking activity adjacent to lane group; $f_{b b}=$ adjustment factor for blocking effect of local buses that stop within intersection area; $f_{a}=$ adjustment factor for area type; $f_{L U}=$ adjustment factor for lane utilization; $f_{L T}=$ adjustment factor for left turns in lane group; $f_{R T}=$ adjustment factor for right turns in lane group; $f_{L p b}=$ pedestrian adjustment factor for left-turn movements; and $f_{R p b}=$ pedestrian-bicycle adjustment factor for right-turn movements for determining saturation flow.

In this procedure, it is difficult to determine the proper adjustment factor which will be used in the calculations. For that reason, traffic engineers usually prefer direct measurement of saturation flow in the field.

The saturation flow rate is the maximum discharge rate during the green time. It is usually achieved after about 10 to 14 seconds of green time, which corresponds to passing time of the front axle of the fourth to sixth passenger car crossing the stop line after the beginning of green [1]. The headway measurements are taken cycle by cycle. In the headway measurement based approach, the saturation flow rate is determined by observations in the field and the following formula is used. 
$S=\frac{3600}{h_{s}}$

where; $h_{s}$ is the average headway of vehicles (sec) after the fourth passenger car.

In the Canadian case, all surveyed vehicles are converted to pcu before processing of the data. Details are defined in the Canadian Capacity Guide. For practical use, a relationship for determination of saturation flow is defined between the Canadian Capacity Guide (CCG) and the Highway Capacity Manual (HCM). The 2000 Highway Capacity Manual defines the time reference for saturation flow surveys as the front axle passing over the stop line [1]. Moreover, the measurement starts with the time of entry of the fourth vehicle in the queue. The definitions of the effective green interval and lost time in the CCG and in the HCM also differ. As a result, the saturation flow and the effective green interval determined by the HCM method is higher than its corresponding value measured by the procedure described in the CCG [2]. The computational techniques in each document are consistent in the application of the respective definition, but the measured values are therefore not directly transferable between both documents. An approximate regression relationship between both saturation flow types in typical conditions has been determined in the CCG. This relation is defined in the following:

$S_{H C M}=1.05 S_{C C G}$,

where:

$S_{H C M}=$ approximate value of the saturation flow corresponding to the HCM method (veh/h). The vehicles in this case are passenger cars only.

$S_{C C G}=$ saturation flow measured or calculated using the methods described in this guide $(\mathrm{pcu} / \mathrm{h})$.

Many researchers suggest different procedures for determining saturation flow and some of them are summarized in Table 1.

Some of the saturation flows determined with these studies obtained from literature are listed in Table 2.

Table 2 reveals that saturation flow varies from a country to the others. One of the main reasons of this variation is related to driver behaviour and traffic conditions. For the case of India, there are some motorcycles, cycles and pedestrians in the traffic stream. Drivers should adopt these units and should also ride slowly. Thus the saturation flow rates are lower in India than other countries. Similar findings and comments can be gathered from literature.
Table 1 Saturation flow calculation procedures - basic data [33]

\begin{tabular}{|c|c|c|c|}
\hline Procedure & $\begin{array}{l}\text { Number } \\
\text { of base } \\
\text { saturation } \\
\text { flow value }\end{array}$ & Definition of base values & $\begin{array}{l}\text { Number of } \\
\text { reduction } \\
\text { factors }\end{array}$ \\
\hline $\begin{array}{l}\text { Webster - } \\
1963\end{array}$ & $1^{*}$ & $\begin{array}{l}\text { Defined in terms of intersection } \\
\text { approach width }\end{array}$ & 7 \\
\hline CCG-2008 & 30 & Defined in terms of $\mathrm{pcu} / \mathrm{h}$ & 13 \\
\hline $\begin{array}{l}\text { HCM - } \\
2000\end{array}$ & 1 & $\begin{array}{l}\text { Unique, uniform value for all } \\
\text { cases }\end{array}$ & 11 \\
\hline $\begin{array}{l}\text { HBS - } \\
2001\end{array}$ & 3 & $\begin{array}{l}\text { Defined on the basis of average } \\
\text { headway value for different } \\
\text { lengths of green phase duration }\end{array}$ & $2(5)^{* *}$ \\
\hline $\begin{array}{l}\text { Akçelik - } \\
1980\end{array}$ & 9 & $\begin{array}{l}\text { Defined in the function of } \\
\text { traffic lane use and type of } \\
\text { intersection environment }\end{array}$ & 4 \\
\hline $\begin{array}{l}\text { DANCAP } \\
-2002\end{array}$ & 4 & $\begin{array}{l}\text { Defined in the function of } \\
\text { average headway value for } \\
\text { various types of movement at } \\
\text { intersection }\end{array}$ & 2 \\
\hline $\begin{array}{l}\text { Finnish } \\
\text { model - } \\
1996\end{array}$ & 6 & $\begin{array}{c}\text { Defined in terms of traffic lane } \\
\text { use }\end{array}$ & 5 \\
\hline $\begin{array}{l}\text { Stanić - } \\
1991\end{array}$ & 3 & $\begin{array}{l}\text { Defined in terms of signal plan } \\
\text { type and traffic lane use }\end{array}$ & 4 \\
\hline
\end{tabular}

* defined in terms of geometric layout

** 2 quantificational most influential ones out of the offered 5 are used in the model

Table 2 Overview of saturation flow rate by different sources [33, 34]

\begin{tabular}{|c|c|c|}
\hline Source & Country & Saturation Flow( veh/h) \\
\hline Webster\&Cobbe & England & 1800 \\
\hline Kimber et al & England & 2080 \\
\hline Miller & Australia & 1710 \\
\hline Branston & England & 1778 \\
\hline H.E.L & Greece & 1972 \\
\hline Shoukry\&Huizayyin & Egypt & 1617 \\
\hline Hussain & Malaysia & 1945 \\
\hline Coeyman\&Meely & Chili & 1603 \\
\hline $\begin{array}{l}\text { Bhattacharya\& } \\
\text { Bhattacharya }\end{array}$ & India & 1232 \\
\hline De Andrade & Brazil & 1660 \\
\hline HCM (1965) & USA & $1500-2000$ \\
\hline CCG (2008) & Canada & $1500-2100 *$ \\
\hline Davies & England & 1325 \\
\hline Kapali & Serbia & 1714 \\
\hline $\mathrm{TRB}$ & USA & 1800 \\
\hline Akçelik & Australia & $1270-1850$ \\
\hline Vini, Pretty & Canada & 1800 \\
\hline RIST & Germany & $1800-2000$ \\
\hline Stanić & Serbia & $1600-2120$ \\
\hline Kehittämiskeskus & Finland & 1750 \\
\hline HBS & Germany & 2000 \\
\hline DANCAP & Denmark & 2000 \\
\hline
\end{tabular}


Saturation flow rate is also used to determine capacity. The capacity of signalized intersection is defined as;

$C=\left(\frac{g}{c}\right) S$,

where; $C=$ capacity in vehicles per hour; $g=$ effective green time in seconds; $c=$ cycle time in seconds and $S=$ saturation flow in vehicles per hour.

As seen on the equation, capacity is directly affected by saturation flow value. Inaccurate or random assignment of saturation flow value leads to erroneous capacity calculations. Therefore, all traffic operations can be affected by this calculation.

\section{The model}

At a signalized intersection vehicles are queued up during the red signal time. In the model, it is assumed that the queue will never end. By the change of the light from red to amber and green, the vehicles will move with a reaction time. The reaction times are assumed to be the same for all of the vehicles.

Definitions of the parameters used in the model are listed in Table 3. In the formula, for compatibility to the literature the symbols are taken from [35]. All of the quantities are considered as an average values in the proposed formula.

$$
\begin{aligned}
& L_{v}=\frac{\sum_{i=1}^{n} L_{v i}}{n} \\
& L_{s j}=\frac{\sum_{i=1}^{n} L_{s j i}}{n} \\
& a_{a}=\frac{\sum_{i=1}^{n} a_{a i}}{n} \\
& t_{a}=\frac{\sum_{i=1}^{n} t_{a i}}{n} \\
& V_{s}=\frac{\sum_{i=1}^{n} V_{s i}}{n} \\
& t_{x}=\frac{\sum_{i=1}^{n} t_{x i}}{n}
\end{aligned}
$$

The total effective time in one-hour period is expressed as $T$. The vehicles that can pass from the intersection line in one hour time period $n$, (meanwhile the saturation flow) will all begin to move after a reaction time which is expressed in $t_{x}$. $n t_{x}+T=3600$

$T=3600-n t_{x}$

The distance that the first vehicle in the queue will move in the effective time, $T$ can be found. That is $L_{T X}$;

$L_{T X}=\frac{1}{2} a_{a} t_{a}^{2}+\left(T-t_{a}\right) V_{s}$

In practice the first vehicle will accelerate to the saturation speed of the intersection, and then pass the intersection with saturation speed after it would accelerate or decelerate according to traffic conditions. For the model it is assumed that as the first vehicle will move at mean intersection speed in effective time, $T$.

The number of the $\left(L_{v}+L_{s j}\right)^{\prime}$ is found in .

$n\left(L_{v}+L_{s j}\right)=\frac{1}{2} a_{a} t_{a}^{2}+\left(T-t_{a}\right) V_{s}$

It is important to note that $\left(L_{v}+L_{s j}\right)$ is expressed as $L_{h j}$ in the literature [35].

If Eq. (13) is re-arranged and substituted into Eq. (11) for $T$, the following expressions can be obtained.

\begin{tabular}{|c|c|c|c|c|c|c|c|c|}
\hline & & Lv & & Lv & & LV & & 崩 \\
\hline $\mathrm{n}$ & 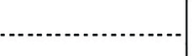 & 3 & Lsj & 2 & Lsj & 1 & Lsj & $j$ \\
\hline
\end{tabular}

$$
\begin{aligned}
& n L_{v}+n L_{s j}=\frac{1}{2} a_{a} t_{a}^{2}+\left(3600-n t_{x}-t_{a}\right) V_{s} \\
& n L_{v}+n L_{s j}=0.5 a_{a} t_{a}^{2}+3600 V_{s}-n t_{x} V_{s}-t_{a} V_{s} \\
& n L_{v}+n L_{s j}+n t_{x} V_{s}=0.5 a_{a} t_{a}^{2}+3600 V_{s}-t_{a} V_{s} \\
& n=\frac{0.5 a_{a} t_{a}{ }^{2}+3600 V_{s}-t_{a} V_{s}}{L_{v}+L_{s j}+t_{x} V_{s}}
\end{aligned}
$$

Fig. 1 Basic presentation of vehicles at a signalized lane

Table 3 Definition of the parameters used in the model [31]

\begin{tabular}{lc}
\hline Symbol & Definition \\
\hline $\mathrm{s}:$ & Saturation flow in vehicles per hour \\
$\mathrm{L}_{\mathrm{v}}:$ & Mean length of the vehicles in the queue in meter \\
$\mathrm{L}_{\mathrm{s} j}:$ & Mean headway of the vehicle in meter \\
$\mathrm{a}_{\mathrm{a}}:$ & Mean acceleration rate of the vehicles in $\mathrm{m} / \mathrm{sec}^{2}$ \\
$\mathrm{t}_{\mathrm{a}}:$ & Time to reach saturation speed of the intersection in seconds \\
$\mathrm{V}_{\mathrm{s}}:$ & Saturation speed of the intersection in $\mathrm{m} / \mathrm{sec}$ \\
$\mathrm{t}_{\mathrm{x}}:$ & Mean reaction time of the vehicles in the queue $(\mathrm{sec})$ \\
\hline
\end{tabular}


Speed $\left(v_{t}\right)$ is the distance that the traffic flow passes in unit time. The vehicles in traffic flow do not move with the same speed therefore in practice the average speed is utilized.

$v_{t}=\left(\frac{1}{n_{a}}\right) \sum_{i=1}^{n} v_{i}$

Density $(k)$ is the number of vehicles within a set on a part of road measured in an instant time. At the same time, it could be expressed as the reciprocal of the distance headway of two sequential vehicles. The observations are generally performed in the distance of $1 \mathrm{~km}$ or $1000 \mathrm{~m}$.

$k=\frac{n_{a}}{L_{a}}=\frac{1000}{L_{h j}}$

Flow $(q)$ is the number of the vehicles passing a point on the road in unit time. It could be found by multiplying speed and density.

$q=v_{t} k$,

$q=v_{t} \frac{1000}{L_{h j}}$,

where $n_{a}$ is the number of the vehicles observed, $L_{a}$ is the length of the observed road section in $\mathrm{km}$, as described before $L_{h j}$ is $\left(L_{v}+L_{s j}\right)$ in meter. So the Eq. (21) can be expressed as;

$q=v_{t} \frac{1000}{L_{h j}}=\frac{1000 v_{t}}{L_{v}+L_{s j}}$.

In ideal freeway conditions;

$a_{a}=0$ no acceleration, no deceleration;

$t_{a}=0$ no acceleration time, no deceleration time;

$t_{x}=0$ the movement is continuous, no reaction;

Hence Eq. (17) becomes;

$n=\frac{3600 V_{s}}{L_{v}+L_{s j}}$.

$v_{t}$ is in $\mathrm{km} / \mathrm{h}$ in Eq. (22) and $V_{s}$ is in $\mathrm{m} / \mathrm{sec}$ in Eq. (23). Equation (23) shows a simplified equation used to calculate saturation flow value. Saturation flow value may be determined (more accurately) using the mean length, mean headway and saturation speed of vehicles.

In Eq. (23), the main reason of the usage of distance headway instead of time gap is to take accounts the traffic composition directly in the model. The saturation flow value is changed based on the traffic composition. These effects are considered in different ways by the conventional methods. In HCM, heavy vehicle factor (fHV) is regarded for traffic composition. The rates of heavy vehicles are used for adjustment in this approach. Although this approach gives some reasonable results, it does not reflect the real case. But in the proposed approach, the length of the vehicles and distance headways are directly considered for saturation flow. Thus, there is no need to determine any rate of heavy vehicles for saturation flow; it may be obtained directly by this way. On the other hand, to obtain saturation flow value more precisely, observations about the vehicle headways (either time gap or distance) are required. Both time gaps and distance headways are not constant; those values are changed based on the traffic conditions and driver behaviors. In the paper submitted, it is tried to regard another point of view. Therefore distance headway is used instead of time gap.

As presented in the Table 1, previous approaches include many parameters that require calibration before usage. On the other hand, the following conditions should be valid in the field for an accurate measurement:

- Not many heavy vehicles in traffic

- Adequate vehicle queue length for the cycle

- Adequate reaction times of drivers

These conditions cannot be met in every time and the saturation flow obtained (by previous approaches) in the field can be approximate. Therefore this study is employed.

\section{Field studies}

\subsection{Data collection}

Two types of data sets were used in the study. The first data set was obtained from observations at two intersections located in Izmir, Turkey. A signalized intersection with four legs was observed. The traffic flows at peak hours was recorded by a camera. Then the records were analyzed to obtain the data needed. In the analysis, the data including mean length, headway and acceleration rate of vehicles, saturation speeds of intersection and mean reaction time of vehicles in queue were obtained.

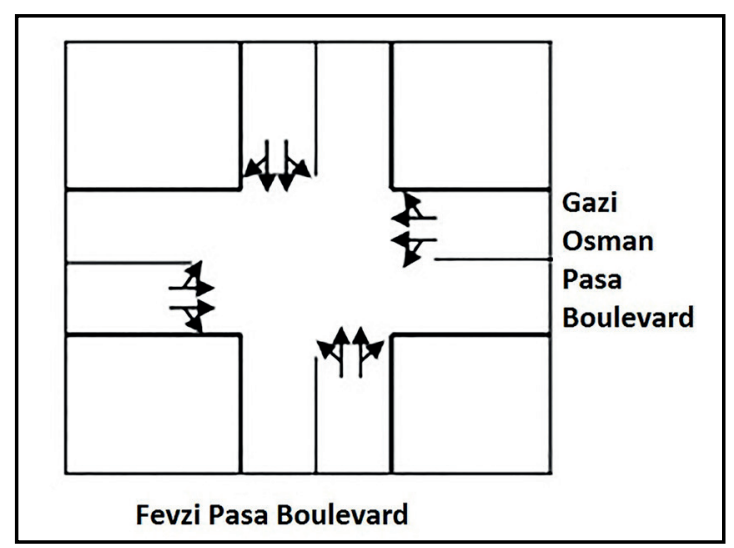

Fig. 2 The observed intersection in Izmir 
Table 4 Comparisons of the models using field observations

\begin{tabular}{|c|c|c|c|c|c|c|c|}
\hline & & \multicolumn{3}{|c|}{ Morning Period } & \multicolumn{3}{|c|}{ Evening Period } \\
\hline & & Right Lane & Middle Lane & Left Lane & Right Lane & Middle Lane & Left Lane \\
\hline \multirow[t]{6}{*}{ Data used for Equation 17} & $\mathrm{~V}_{\mathrm{s}}(\mathrm{m} / \mathrm{s})$ & 5.45 & 6.31 & 6.94 & 5.24 & 6.39 & 7.23 \\
\hline & $\mathrm{L}_{\mathrm{v}}(\mathrm{m})$ & 7.5 & 5.5 & 5.5 & 7.5 & 5.5 & 5.5 \\
\hline & $\mathrm{L}_{\mathrm{sj}}(\mathrm{m})$ & 2 & 2 & 1.5 & 2 & 2 & 1.5 \\
\hline & $t_{x}(s)$ & 1.5 & 1 & 1 & 1.5 & 1 & 1 \\
\hline & $\mathrm{a}_{\mathrm{a}}\left(\mathrm{m} / \mathrm{s}^{2}\right)$ & 1.09 & 1.26 & 1.39 & 1.05 & 1.28 & 1.45 \\
\hline & $\mathrm{t}_{\mathrm{a}}(\mathrm{s})$ & 5 & 5 & 5 & 5 & 5 & 5 \\
\hline Measured headway & (hs)(s) & 3.24 & 2.25 & 2.04 & 3.19 & 2.21 & 2.02 \\
\hline HCM method & $(\mathrm{veh} / \mathrm{h})$ & 1189 & 1678 & 1756 & 1100 & 1594 & 1702 \\
\hline CCG method & $(\mathrm{pcu} / \mathrm{h})$ & 1132 & 1598 & 1672 & 1047 & 1514 & 1622 \\
\hline Field Observation & (veh/h) & 1111 & 1603 & 1765 & 1126 & 1628 & 1784 \\
\hline New Formula & $(\mathrm{veh} / \mathrm{h})$ & 1110 & 1645 & 1792 & 1087 & 1656 & 1829 \\
\hline Difference rate in $\%$ & (HCM - Field Obs.) & 7.00 & 5.02 & -1.05 & 2.08 & -1.98 & -5.03 \\
\hline \multicolumn{2}{|c|}{ Difference rate in \% (New Formula-Field Obs. ) } & 0.09 & 2.79 & 1.93 & -3.06 & 1.97 & 2.95 \\
\hline Difference rate in $\%$ & (CCG -Field Obs.) & 1.94 & 0.04 & -4.98 & -6.82 & -7.08 & -8.96 \\
\hline
\end{tabular}

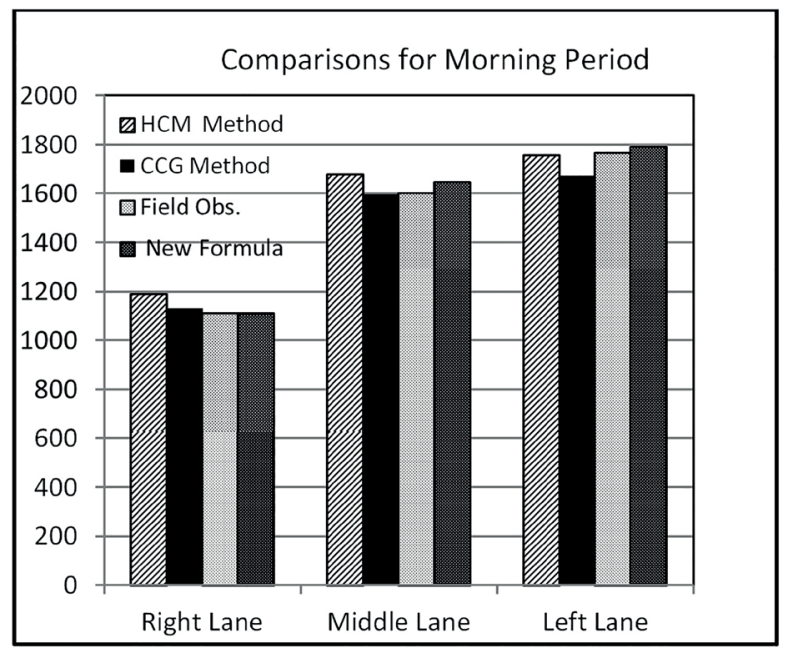

(a)

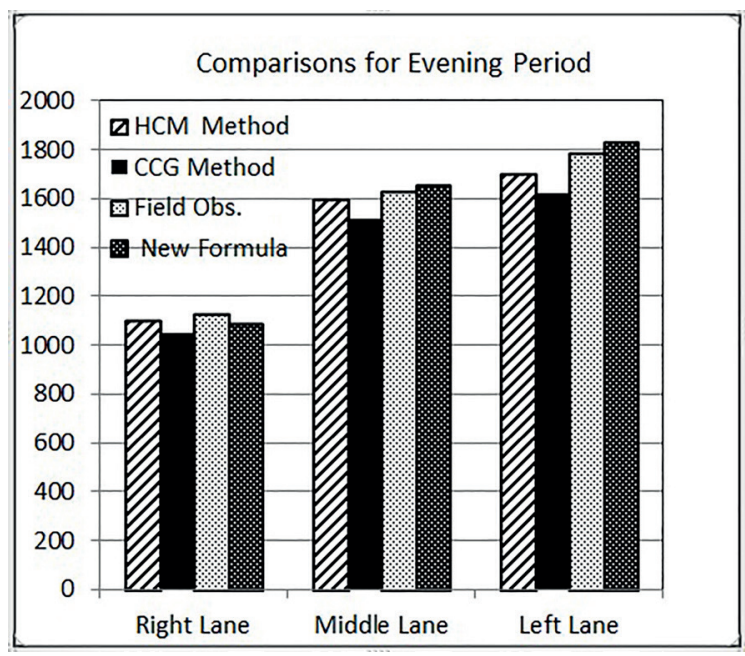

(b)

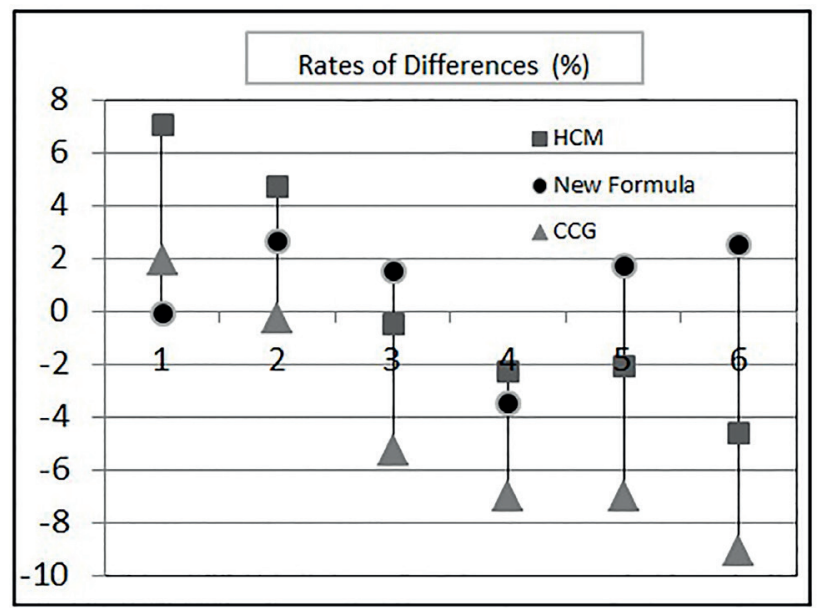

(c)

Fig. 3 Compared saturation flows by different methods for: (a) morning period, (b) evening period, (c) rates of differences 
Table 5 Comparisons of the models using the data obtained from literature

\begin{tabular}{|c|c|c|c|c|c|c|c|c|}
\hline Int. No (1) & Sat. Flow (veh/h) (2) & $\mathrm{a}_{\mathrm{a}}\left(\mathrm{m} / \mathrm{s}^{2}\right)(3)$ & $\mathrm{t}_{\mathrm{a}}(\mathrm{s})(4)$ & $\mathrm{V}_{\mathrm{s}}(\mathrm{m} / \mathrm{s})(5)$ & $\mathrm{L}_{\mathrm{sj}}(\mathrm{m})(6)$ & $t_{x}(s)(7)$ & The New App (9) & Differ Rate $\%(10)$ \\
\hline 1 & 2032 & 1.25 & 5.45 & 6.81 & 2.00 & 0.84 & 2020 & 0.57 \\
\hline 2 & 2083 & 1.74 & 7.20 & 12.53 & 2.50 & 1.17 & 2090 & -0.33 \\
\hline 3 & 1958 & 1.54 & 5.57 & 8.58 & 2.60 & 1.02 & 1960 & -0.09 \\
\hline 4 & 2096 & 1.34 & 5.12 & 6.86 & 1.60 & 0.84 & 2098 & -0.11 \\
\hline 5 & 1965 & 1.23 & 4.92 & 6.03 & 1.50 & 0.85 & 1967 & -0.11 \\
\hline 6 & 1946 & 1.17 & 5.77 & 6.78 & 2.20 & 0.88 & 1940 & 0.29 \\
\hline 7 & 2130 & 1.18 & 6.35 & 7.53 & 2.50 & 0.77 & 2133 & -0.12 \\
\hline 8 & 1786 & 1.42 & 7.70 & 10.97 & 2.40 & 1.40 & 1780 & 0.31 \\
\hline 9 & 1801 & 1.67 & 5.51 & 9.22 & 2.40 & 1.26 & 1801 & 0.00 \\
\hline 10 & 2275 & 1.62 & 9.04 & 14.67 & 2.20 & 1.13 & 2276 & -0.03 \\
\hline 11 & 1885 & 1.19 & 7.42 & 8.81 & 2.60 & 1.11 & 1888 & -0.15 \\
\hline 12 & 1933 & 1.33 & 7.61 & 10.11 & 2.90 & 1.14 & 1931 & 0.08 \\
\hline 13 & 1995 & 1.70 & 7.60 & 12.89 & 2.50 & 1.27 & 1992 & 0.15 \\
\hline 14 & 2416 & 2.07 & 7.20 & 14.94 & 2.60 & 1.02 & 2416 & -0.01 \\
\hline 15 & 2549 & 1.94 & 8.03 & 15.58 & 2.60 & 0.96 & 2552 & -0.11 \\
\hline 16 & 2418 & 1.68 & 7.62 & 12.83 & 2.60 & 0.94 & 2421 & -0.12 \\
\hline 17 & 2208 & 1.49 & 8.94 & 13.31 & 2.60 & 1.10 & 2211 & -0.14 \\
\hline 18 & 1963 & 2.01 & 7.26 & 14.56 & 2.60 & 1.35 & 1964 & -0.06 \\
\hline 19 & 1981 & 1.48 & 5.79 & 8.58 & 2.60 & 1.00 & 1981 & -0.01 \\
\hline 20 & 1804 & 1.48 & 5.08 & 7.53 & 2.60 & 1.07 & 1799 & 0.29 \\
\hline 21 & 2110 & 1.51 & 6.35 & 9.61 & 2.60 & 0.98 & 2105 & 0.22 \\
\hline
\end{tabular}

(8) $\mathrm{L}_{\mathrm{v}}$ is $4.40 \mathrm{~m}$ for all cases

The data were obtained manually from the observations. Although measurements of the parameters mentioned in the new formula seem to be complicated, it could be simpler by new technologies and methods. It can be collected by using a number of new technologies. Use of loop detectors and video cameras (with image processing algorithms) can be helpful in data collection. Vehicle classification (length) and speeds can easily be measured by many types of loop detectors and also video cameras [1]. Additionally, acceleration rates and average reaction times of vehicles can also be measured by these ways. Therefore use of video cameras and loop detectors (if required) could simplify the procedure for practitioners.

\subsection{Validation search}

The saturation flow values that are determined by the New Formula are compared with the HCM method, CCG method and the field observations. The results are presented in Table 4 and Fig. 3.

As seen from Fig 3, general trends of the methods are similar to observations. Results of the new formula are very closing to that of obtained by the headway method in field studies. Therefore, the proposed formula is confirmed by the field observations. However, the results obtained by the HCM and the CCG methods have some differences. The main reason of this difference is the difficulty in assigning correct adjustment factor, especially when lane characters and human behaviours are not homogenous like the intersection observed in this study.

It could be seen from Table 4 that the data $L_{v}, L_{s i}, t_{a}$ and $t_{x}$ used for Eq. (17), are rounded. Determining these characteristics accurately is quite difficult with video records. Some analyses and pre assumptions are made to determine these characteristics. However, for exact determinations more technological systems, like loop detectors, computers and some software are required.

Although initial results are promising, they are not adequate for confirming the new approach. Therefore, the literature is researched to find more data that could be used for confirmation. In the second stage of validation search, the data obtained from the literature are used. The data were collected from a signalized intersection at Melbourne, Australia by Akcelik [35]. The data obtained include the parameters considered in the new formula and 
the saturation flow values measured at the intersection from Melbourne. Using these parameters obtained from the field observations and the new formula, saturation flows are calculated and shown in column 9 of Table 5 .

To evaluate the validation of the new formula, the measured and the calculated saturation flow values are compared. Differences of measured saturation flows and the calculated ones are determined and presented in column 10 of Table 5. Comparisons show that the differences are very small and negligible. Therefore, the new formula may be regarded as an alternative approach for estimation of saturation flows at signalized intersections.

\section{Discussion on the model parameters}

The model parameters and effects on saturation flow are discussed in this section. In the proposed formula, six parameters are considered. Some of these parameters have a (direct or indirect) relation with physical and geometric conditions of field. In Table 6, parameters of the new formula and related physical and other factors are summarized. Physical factors are depicted as $(p)$ in the table.

As seen in the table, three parameters of the new formula as mean headway of the vehicles $\left(L_{s j}\right)$, mean acceleration rate of the vehicles $\left(a_{a}\right)$ and saturation speed of the intersection $\left(V_{s}\right)$ are affected by certain physical conditions of intersections. Approach grade and geometric conditions of intersections are the main factors that can be effective on the parameters.

\subsection{Reaction time $\left(t_{x}\right)$}

Reaction time $\left(t_{x}\right)$ is one of the main parameters that has a significant effect on saturation flows. At a signalized intersection, the first vehicle in the queue begins to move after a reaction time $t_{r}$ to the change of traffic signal from red to amber and green. The other vehicles in the queue follow each other after a reaction time $t_{x}$ for the movement of the front vehicle. In practice $t_{r}$ and $t_{x}$ can be taken equal. It could be derived by dividing the time passes from the change of light by the number of the vehicles.

$t_{x}=\frac{T_{n}}{n}$

Here $T_{n}$ is the time that the $n$th vehicle would begin to move from the changing of signal lights. With this method more than 200 observations were performed in Izmir, Turkey and $t_{x}$ values were measured between 0.7 to 2 seconds. In Table 5 the minimum $t_{x}$ is $0.77 \mathrm{~s}$ and the maximum $t_{x}$ is $1.35 \mathrm{~s}$ and the mean $t_{x}$ is $1.05 \mathrm{~s}$. In Figure 4, the reaction time versus saturation flow relationship is illustrated for practically observed and non-observed smaller values. Here the required data are given in respectively; $a_{a}$ $=1.67 \mathrm{~m} / \mathrm{sec}, t_{a}=5 \mathrm{sec}, V_{s}=8.33 \mathrm{~m} / \mathrm{sec}(30 \mathrm{~km} /$ hour$), L_{s j}=$ $2.00 \mathrm{~m}$ and $L_{v}=4.40 \mathrm{~m}$.

\subsection{Saturation speed of the intersection in $\mathrm{m} / \mathrm{sec}\left(\mathrm{V}_{\mathrm{s}}\right)$}

The saturation speed is another important parameter in determining saturation flows. It can be determined either automatically (detectors, counters, etc) or manually by the time that a vehicle passes between selected two points.

In the field, minimum, maximum and mean saturation speed values are measured as $21.70 \mathrm{~km} / \mathrm{h}, 52.80 \mathrm{~km} / \mathrm{h}$ and $37.49 \mathrm{~km} / \mathrm{h}$, respectively. In some observations that are performed at 20 signalized intersections saturation speeds encountered are varied from 15 to $45 \mathrm{~km} /$ hours.

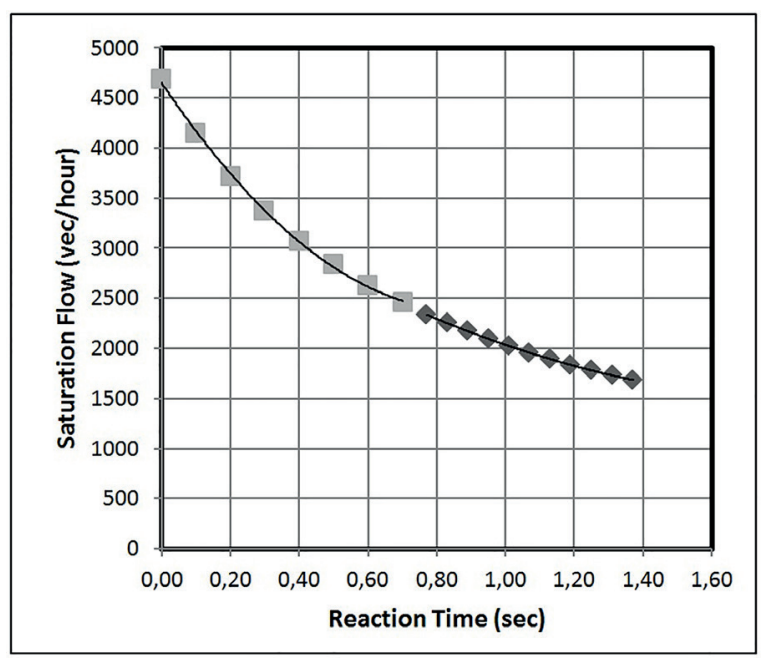

Fig. 4 Relationships between Reaction Time and Saturation Flow

Table 6 The Model Parameters and their effects

\begin{tabular}{|c|c|c|}
\hline Symbol & Definition & Relationship \\
\hline s: & $\begin{array}{c}\text { Saturation flow in vehicle per } \\
\text { hour }\end{array}$ & - \\
\hline $\mathrm{L}_{\mathrm{v}}:$ & $\begin{array}{l}\text { Mean length of the vehicles in } \\
\text { the queue in meter }\end{array}$ & Traffic composition \\
\hline $\mathrm{L}_{\mathrm{sj}}$ : & $\begin{array}{c}\text { Mean headway of the vehicle } \\
\text { in meter }\end{array}$ & $\begin{array}{l}\text { Approach grade }(\mathrm{p}), \\
\text { vehicle type }\end{array}$ \\
\hline$a_{a}:$ & $\begin{array}{c}\text { Mean acceleration rate of the } \\
\text { vehicles in } \mathrm{m} / \mathrm{s}^{2}\end{array}$ & $\begin{array}{l}\text { Approach grade }(p), \\
\text { vehicle type }\end{array}$ \\
\hline$t_{\mathrm{a}}:$ & $\begin{array}{l}\text { Time to reach saturation speed } \\
\text { of the intersection in seconds }\end{array}$ & $\begin{array}{l}\text { Driver behavior, } \\
\text { vehicle type }\end{array}$ \\
\hline $\mathrm{V}_{\mathrm{s}}:$ & $\begin{array}{l}\text { Saturation speed of the } \\
\text { intersection in } \mathrm{m} / \mathrm{s}\end{array}$ & $\begin{array}{l}\text { Traffic condition, } \\
\text { geometric condition }(\mathrm{p})\end{array}$ \\
\hline$t_{x}:$ & $\begin{array}{l}\text { Mean reaction time of the } \\
\text { vehicles in the queue (s) }\end{array}$ & Driver behavior \\
\hline
\end{tabular}


Table 7 Presumptions to analyze the effect of speed

\begin{tabular}{lccccc}
\hline $\mathrm{V}_{\mathrm{s}}(\mathrm{km} / \mathrm{h})$ & $\mathrm{L}_{\mathrm{sj}}(\mathrm{m})$ & $\mathrm{L}_{\mathrm{v}}(\mathrm{m})$ & $\mathrm{t}_{\mathrm{x}}(\mathrm{s})$ & $\mathrm{a}_{\mathrm{a}}\left(\mathrm{m} / \mathrm{s}^{2}\right)$ & $\mathrm{t}_{\mathrm{a}}(\mathrm{s})$ \\
\hline 0 & 2.00 & 4.40 & 1.00 & 0 & 0 \\
5 & 2.00 & 4.40 & 1.00 & 2.78 & 0.50 \\
10 & 2.00 & 4.40 & 1.00 & 1.85 & 1.50 \\
15 & 2.00 & 4.40 & 1.00 & 1.74 & 2.40 \\
20 & 2.00 & 4.40 & 1.00 & 1.68 & 3.30 \\
25 & 2.00 & 4.40 & 1.00 & 1.65 & 4.20 \\
30 & 2.00 & 4.40 & 1.00 & 1.60 & 5.20 \\
35 & 2.00 & 4.40 & 1.00 & 1.52 & 6.40 \\
40 & 2.00 & 4.40 & 1.00 & 1.48 & 7.50 \\
45 & 2.00 & 4.40 & 1.00 & 1.44 & 8.70 \\
50 & 2.00 & 4.40 & 1.00 & 1.39 & 10.00 \\
55 & 2.00 & 4.40 & 1.00 & 1.33 & 11.50 \\
60 & 2.00 & 4.40 & 1.00 & 1.28 & 13.00 \\
\hline
\end{tabular}

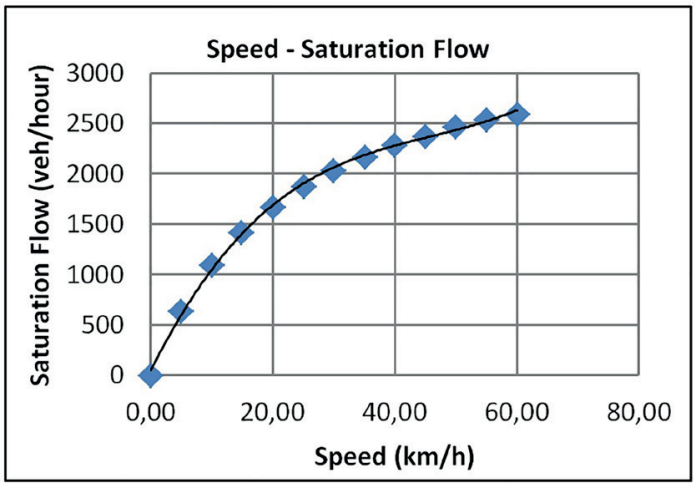

Fig. 5 Relationships between Saturation Speed and Saturation Flow

Based on the observations it can be expressed that saturation speed depends on mostly; the intersection geometry, density, traffic condition, lane width, signal timing and vehicle properties.

Determining the interaction of saturation flow with saturation speed in the proposed formula is not so simple. To handle this problem some assumption were made. With the change of the saturation speed, time to reach saturation speed $\left(t_{a}\right)$ and acceleration rate $\left(a_{a}\right)$ will change. To determine the effect of speed pre assumptions for the values of ta and aa are made and it is expressed in Table 7. Relationship between saturation speeds and saturation flows are depicted in Fig. 5. However acceleration rate and acceleration time change with the saturation speed and it must be outlined that saturation flow rates are not directly affected by acceleration time.

The relationship depicted on Fig. 5 is based on the data given in Table 7. These data (Table 7) are obtained by some assumptions. Therefore, some limited traffic conditions (state) are only represented in Fig. 5. It cannot be generalized for all traffic conditions (saturated, unsaturated and mixed traffic state). More data and detailed observations are needed to generalize and expand this figure.

\subsection{Vehicle length $\left(L_{v}\right)$ and headway $\left(L_{s j}\right)$}

Saturation flow is directly affected by vehicle lengths and vehicle headway. It must be noted that although saturation flow is represented by the number of vehicles passing in one hour (veh/h), the formula proposed here uses the number of the mean vehicle length in one hour. In the past, various approaches have been adapted for estimation of Passenger Car Unit (PCU) or Passenger Car Equivalent (PCE) values of vehicles (Akcelik et al.).

In the case of car dominated traffic composition, like city centers, this approach might be convenient. Otherwise PCE conversion approach always has some disadvantages. In the literature many studies were achieved for determining the effect of heavy vehicles. Many reduction coefficients are proposed for regarding their effect on saturation flow. But the properties that are changing with vehicle length or vehicle type like speed, acceleration, reaction time are also taken into account in Eq. (17). So, there is no need to use PCE's or any other reduction coefficients in the proposed formula.

Determining the mean length of the vehicle is a problem in saturation flow estimation. For example, Akçelik used $4.40 \mathrm{~m}$ mean length for cars in Australia [35]. In Turkey, mean car length is observed above 4 meters. However in Malaysia researchers suggest different vehicle lengths based on vehicle type [36].

Vehicle headway is considered as the distance between the rear bumper of the front vehicle and the front bumper of the following vehicle in meters. Determining average headway is another difficulty in saturation flow phenomenon. In jammed traffic vehicles move bumper to bumper. In this case the headway might be smaller than $1 \mathrm{~m}$. But when traffic conditions improve headways become larger.

To illustrate the effects of vehicle length and headway, the following presumptions are made; $V_{s}=30 \mathrm{~km} / \mathrm{h}, t_{x}=$ $1.00 \mathrm{~s} ., a_{a}=1.60 \mathrm{~m} / \mathrm{s}, t_{a}=5.2 \mathrm{~s}$, and for mean length $L_{s j}=$ $2.00 \mathrm{~m}$., for mean headway $L_{v}=4.40 \mathrm{~m}$. Fig. 6 shows the relations of saturation flow, mean vehicle length and mean vehicle headway.

\subsection{Acceleration rate $\left(a_{a}\right)$, Acceleration time $\left(t_{a}\right)$}

Acceleration rate and acceleration time are primarily dependent on saturation speed. Increase of the saturation speed can cause a decrease in the acceleration rate. At the 
same time the acceleration time would be longer. In the field observations in Izmir, an average acceleration rate of $1.3 \mathrm{~m} / \mathrm{s}$ and acceleration time of $5 \mathrm{~s}$ are obtained.

\subsection{Traffic composition (vehicle length), saturation speed $\left(V_{s}\right)$ and reaction time $\left(t_{r}\right)$}

Effects of traffic composition, saturation speed and reaction time are also investigated in the study. Three types of vehicles are taken into consideration as $\mathrm{A}, \mathrm{B}$ and $\mathrm{C}$. These classifications have been made regarding vehicle lengths. In addition to vehicle lengths, saturation speeds and reaction times of vehicles are used in determination of saturation flow values. The parameters used in the calculations are given in Table 8 .

The relationships of these parameters are investigated and the results obtained are indicated in Figures 7. As seen on the figures, saturation flow values are decreased when the vehicle lengths are increased. These results indicate that with the increase of the ratio of smaller vehicles in the traffic would cause an increase in capacity of intersections. Similar relations may easily be inferred from the figures (Fig 7) for reaction times and saturation flow values.

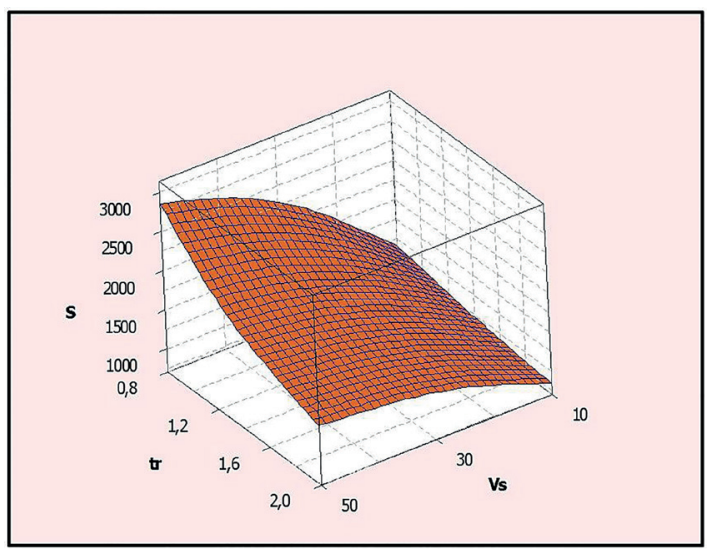

(a)

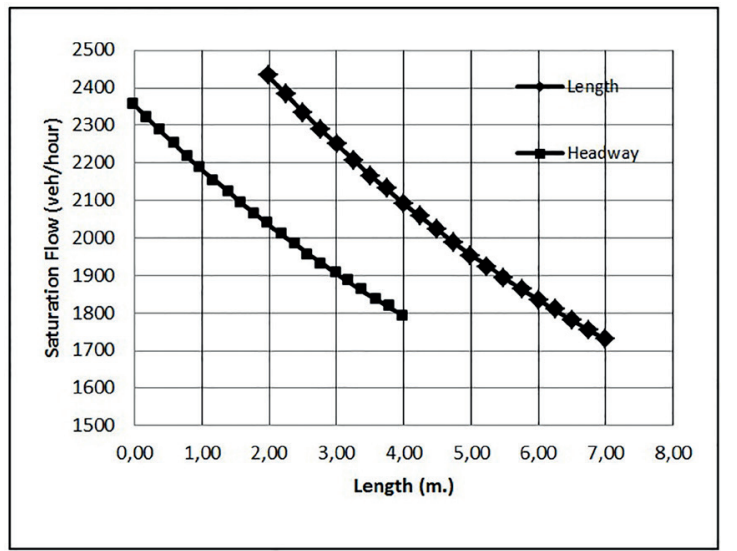

Fig. 6 Relationships among Saturation Flow, Vehicle Length and Vehicle Headway

Table 8 Vehicle Type (Length), saturation speed and reaction time parameters

\begin{tabular}{cccccccccccc}
\hline $\begin{array}{c}\text { Vehicle Type } \\
(\mathrm{Lv}-\mathrm{m} .)\end{array}$ & $\begin{array}{c}\mathrm{L}_{\mathrm{sj}} \\
(\mathrm{m} .)\end{array}$ & $\begin{array}{c}\mathrm{V}_{\mathrm{s}} \\
(\mathrm{km} / \mathrm{h})\end{array}$ & $\begin{array}{c}\mathrm{a}_{\mathrm{a}} \\
\left(\mathrm{m} / \mathrm{sec}^{2}\right)\end{array}$ & $\begin{array}{c}\mathrm{t}_{\mathrm{a}} \\
(\mathrm{sec})\end{array}$ & \multicolumn{4}{c}{$\begin{array}{c}\mathrm{tr} \\
(\mathrm{sec})\end{array}$} & \\
\hline $\mathrm{A}$ & $\mathrm{B}$ & $\mathrm{C}$ & & & & & & & & & \\
4.40 & 5.50 & 7.00 & 2.00 & 10 & 1.50 & 1.85 & 0.8 & 1.2 & 1.6 & 2.0 \\
4.40 & 5.50 & 7.00 & 2.00 & 30 & 1.50 & 5.56 & 0.8 & 1.2 & 1.6 & 2.0 \\
4.40 & 5.50 & 7.00 & 2.00 & 50 & 1.50 & 9.26 & 0.8 & 1.2 & 1.6 & 2.0 \\
\hline
\end{tabular}

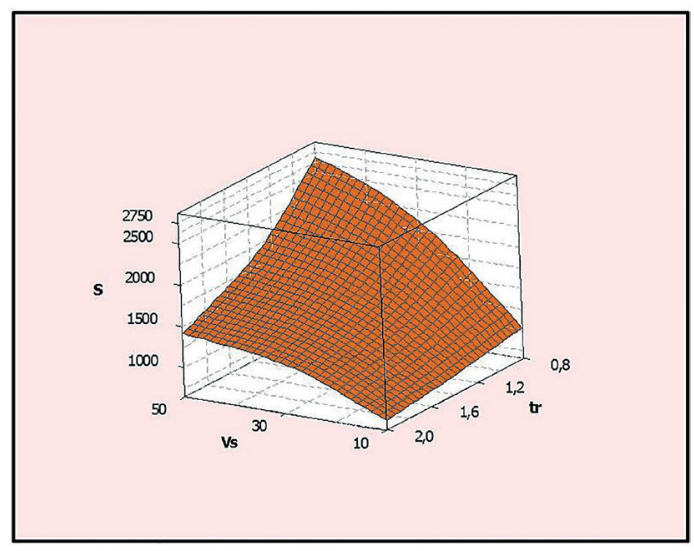

(b)

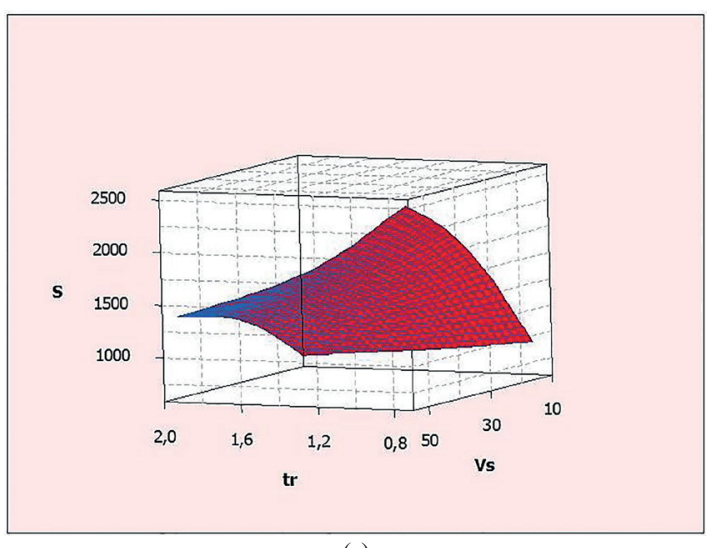

(c)

Fig.7 Relations of Vehicle Type (Length), saturation speed and reaction time parameters for (a) Vehicle Type A, (b) Vehicle Type B, (c) Vehicle Type C 


\section{Conclusions}

This study attempts to introduce a new perspective for estimation of saturation flow that is one of the fundamental parameters used for defining level of service, determination of signal timings and other traffic operations. The new approach summarizes the effects of human factors and vehicle characteristics on saturation flow.

In the proposed formula, mean length, headway and acceleration rate of vehicles, saturation speeds of intersection and mean reaction time of vehicles in a queue are considered. The formula is tested with field data and compared to the values obtained by the HCM and the CCG approach. The comparisons show that, the results of the new formula very close to that of provided by the conventional headway observation methods and it is inferred that there is not any significant difference between the new formula and field observations.

The parameters considered in the proposed formula are also evaluated and some critical findings are reported in the following:

- Reaction time is the major factor in saturation flow. Although practically reaction times do not fall below $0.8 \mathrm{~s}$, if we could decrease this value with new technologies saturation flow would be over than 3000 $\mathrm{veh} / \mathrm{h}$.

- The results show that reaction time can be used as 0.85 seconds for an intersection that has ideal geometric conditions otherwise it can be used as 1.25 seconds.

- Saturation speed is one of the main parameters in saturation flow. In practical traffic conditions saturation flow is obtained as $1419 \mathrm{veh} / \mathrm{h}$ for the value of $20 \mathrm{~km} / \mathrm{h}$ saturation speed while it is $2170 \mathrm{veh} / \mathrm{h}$ for $40 \mathrm{~km} / \mathrm{h}$.

- Vehicle length is also an important factor for saturation flow. A traffic composition with longer vehicles would cause smaller saturation flows and low capacity. In practice, average vehicle length varies from 4.00 to 4.57 meters in different countries. If the average vehicle length can be decreased to a value of 3.60 meters saturation flow could easily rise about $10 \%$.

- Mean vehicle headway is generally accepted about 2.00 meters. If it can be reduced as about 1.00 meter, saturation flow would rise about $5 \%$.

The major advantage of new approach is to determine saturation flow accurately with a basic speed measurement in known traffic composition using Eq (23).
These results indicate that with the increase of the ratio of smaller vehicles in the traffic would cause an increase in capacity of intersections. For future works, to generalize the results obtained in this study much more observations including different traffic conditions should be made in the field.

\section{References}

[1] Transportation Research Board "Highway Capacity Manual 2000", National Research Council, Washington, D.C., Unites States, 2000.

[2] Teply, S., Jones, A. M. "Saturation Flow: Do We Speak the Same Language", Transportation Research Record, 1320, pp. 144-153, 1991. Available at: http://onlinepubs.trb.org/Onlinepubs/trr/1991/ 1320/1320-018.pdf [Accessed: 01.02.2019]

[3] Giannopoulos, G., Mustafa M. "Saturation Flow and Capacity of Shared Lanes: Comparative Evaluation of Estimation Methods", Transportation Research Record, 1555, pp. 50-58, 1996. https://doi.org/10.3141/1555-07

[4] Rouphail, N., Nevers, B. "Saturation Flow Rate Using Traffic Subgroups", Transportation Research Record, 1776, pp. 114-122, 2001.

https://doi.org/10.3141/1776-15

[5] Bonneson J., Nevers B., Zegeer J., Nguyen T., Fong T. "Guidelines for quantifying the influence of Area Type and other factors on saturation flow rate", Texas Transportation Institute, College Station, Texas, United States, Final report, 2005.

[6] Prassas, E., McShane, W., Roess, R. "Stochastic Modeling of Shared-Lane Left-turn Process and Its Effect on Saturation Flow", Transportation Research Record, 1555, pp. 105-113, 1996. https://doi.org/10.3141/1555-14

[7] Li, H., Prevedouros, P. "Detailed Observations of Saturation Headways and Start-up Lost Times", Transportation Research Record, 1802, pp. 44-53, 2002. https://doi.org/10.3141/1802-06

[8] Xuan, Y., Daganzo, C. F., Cassidy, M. J. "Increasing the capacity of signalized intersections with separate left turn phases", Transprtation Resarch Part B, 45(5), pp. 769-781, 2011.

https://doi.org/10.1016/j.trb.2011.02.009

[9] Chen, P., Nakamura, H., Asano, M. "Analysis of Saturation Flow Rate Fluctuation for Shared Left-turn Lane at Signalized Intersections in Japan: A Case Study", Procedia - Social and Behavioral Sciences, 2011. [online] Available at https:/www.researchgate.net/publication/251714024_Saturation_Flow_Rate_Analysis_for_Shared_ Left-turn_Lane_at_ignalized_Intersections_in_Japan [Accessed 04.02.2019]

[10] Shao, C.-Q., Rong, J., Liu, X.-M. "Study on the saturation flow rate and its influence factors at signalized intersections in China", Procedia - Social and Behavioral Sciences, 16, pp. 504-514, 2011. https://doi.org/10.1016/j.sbspro.2011.04.471

[11] Hossain, M. "Estimation of saturation flow at signalized intersections of developing cities: a microsimulation modelling approach", Transportation Research Part A: Policy and Practice, 35(2), pp. 123$141,2001$. https://doi.org/10.1016/S0965-8564(99)00050-6 
[12] Susilo, B. H., Solihin Y. "Modification of Saturation Flow Formula by Width of Road Approach", Procedia Social and Behavioral Sciences, 16, pp. 620-629, 2011.

https://doi.org/10.1016/j.sbspro.2011.04.482

[13] Shang, H., Zhang, Y., Fan, L. "Heterogeneous Lanes' Saturation Flow Rates at Signalized Intersections", Procedia - Social and Behavioral Sciences 138, pp. 3-10, 2014. https://doi.org/10.1016/j.sbspro.2014.07.175

[14] Murat, Y. S., Gedizlioglu, E. "Investigation of Vehicle Time Headways in Turkey", Institute of Civil Engineers - Transport, 160(2), pp. 73-78, 2007. https://doi.org/10.1680/tran.2007.160.2.73

[15] Shikata, S., Katakura, M., Oguchi, T., Kawai, Y. "The relation between saturation flow and Lane width of approach at signalized intersections", Infrastructure Planning Review, 18, pp. 943-947, 2001. (in Japanese) https://doi.org/10.2208/journalip.18.943

[16] Joseph, J., Chang, G.-L. "Saturation flow rates and maximum critical lane volumes for planning applications in Maryland", Journal of Transportation Engineering, 131(12), pp. 946-952, 2005. https://doi.org/10.1061/(ASCE)0733-947X(2005)131:12(946)

[17] Lin, F.-B., Thomas, D. "Headway compression during queue discharge at signalized intersection", Journal of the Transportation Research Board, 1920, pp. 81-85, 2005. https://doi.org/10.3141/1920-10

[18] Radhakrishnan, P., Mathew, T. V. "Passenger car units and saturation flow models for highly heterogeneous traffic", Transportmetrica, 7(2), pp. 141-162, 2011. https://doi.org/10.1080/18128600903351001

[19] Hadiuzzaman, M. "Development of saturation flow and delay models for signalized intersection in Dhaka City", MS Thesis, Bangladesh University of Engineering and Technology, 2008.

[20] Stewart, J. A., Hodgson, K. "Estimation of right turn on red saturation flow rates", Canadian Journal of Civil Engineering, 22(3), pp. 535-543, 1995 . https://doi.org/10.1139/195-062

[21] Rahman, M. M., Nur-Ud-Deen, A. S., Hassan, T. "Comparison of saturation flow rate at signalized intersections in Yokohama and Dhaka", Proceedings of the Eastern Asia Society for Transportation Studies, 5, pp. 959-966, 2005. [online] Available at https://pdfs.semanticscholar.org/109e/b0686902a154d9715407ef788a66ef30f4d9.pdf [Accessed: 04.02.2019]

[22] Vien, L. L., Ibrahim, W. H., Sadullah, A. F. "Passenger car equivalents and saturation flow rates for through vehicles at signalized intersections in Malaysia", presented at 22th ARRB Conference-Research into Practice, Canberra, Australia, October 29 - November 02, 2006.

[23] Federal Highway Administration, "Traffic Control System Handbook", [pdf] Washington, D.C., United States, 2005. Available at https://ops.fhwa.dot.gov/publications/fhwahop06006/fhwa_hop_06 _006.pdf [Accessed: 04.02.2019]

[24] Cetin, M., Murat, Y. S."Doygun Akimin Belirlenmesinde Surucu Davranislarina Bagli bir Matematik Model" (A Mathematical Model Including Driver Behaviours for Determining Saturation Flows), Technical Journal of Turkish Chamber of Civil Engineers, 24(2), pp. 4759-4777, 2013. (in Turkish) Available at: http://www.imo. org.tr/resimler/dosya_ekler/618e255f127da1e_ek.pdf?dergi=477 [Accessed: 05.02.2019]
[25] Stanić, B., Tubić, V., Čelar, N. "Straight Lane Saturatıon Flow and Its Rate in Serbian Cities", Transport, 26(3), pp. 329-334, 2011. https://doi.org/10.3846/16484142.2011.623762

[26] Bester, C. J., Meyers, W. L. "Saturation Flow Rates", presented at 26th Southern African Transport Conference (SATC 2007), Pretoria, South Africa, July, 9-12, 2007. Available at https://repository.up.ac. za/bitstream/handle/2263/5838/002.pdf\%3Bjsessionid\%3D4FCD4E6450E063E61E9B0269F28C571E?sequence\%3D1 [Accessed: 04.02.2019]

[27] Akcelik, R., Besley, M. "Queue Discharge Flow and Speed Model for Signalized Intersections", presented at 15th International Symposium on Transportation and Traffic Theory, Adelaide, Australia, July, 16-18, 2002. Available at http://www.sidrasolutions. com/Documents/Akcelik_ISTTT15_2002_Paper.pdf [Accesed: 04.02.2019]

[28] Arasan, V. T., Arkatkar, S. S. "Microsimulation study of vehicular interactions in heterogeneous traffic flow on intercity roads", European Transport (Trasporti Europei), 48(16), pp. 60-86, 2011. Available at https://www.openstarts.units.it/bitstream/10077/ 6179/1/48D_ArasanArkatkar.pdf [Accessed: 04.02.2019] 